\title{
Research on the cross-border traffic control operation mode of the Hong Kong-Zhuhai-Macao Bridge
}

\author{
SHENG Gang ${ }^{1, ~ a, ~ Y U ~ J i a-q i n g, ~} 2$, , , \\ ${ }^{1}$ Chang An University, Xi'an Shanxi 710064, China \\ ${ }^{2}$ Research Institute of Highway Ministry of Transport, Beijing 100088, China \\ ag.sheng@rioh.cn, bjq.yu@rioh.cn
}

Keywords: traffic control; operation mode; organizational structure; HZMB.

Abstract. As the large cross-border infrastructure connecting the Mainland, Hong Kong, Macao and Taiwan, the Hong Kong-Zhuhai-Macao Bridge (HZMB) displays some distinctive features and unique requirements for the different systems and management mode. Based on the analysis of the cross-border traffic control organization structure and related departments, the title of the liaison officer is created, the operating system of liaison mechanism is laid down, and the layered cross-border traffic control operation mode is built according to the location and severity of the event, the impact of traffic flow and the traffic control scope.

\section{Introduction}

The in-construction HZMB which consists of a series of bridges and tunnels will connect Hong Kong, Macau and Zhuhai, three major cities on the Pearl River Delta in East Asia [1,2]. The proposed $50 \mathrm{~km}$ link, with an estimated investment of 72.94 billion Yuan and a designed service life of 120 years, consists three parts: Offshore Bridge-cum-Tunnel, Boundary Crossing Facilities (BCF) at Hong Kong, Zhuhai and Macao, and Link Roads in these three regions [3]. When completed, it'll become the longest six-lane immersed tube tunnel, and the longest cross-sea bridge and tunnel combined highway in the world.

The particular policy of "One Country, Two Systems" and the dissimilarities among the legal system, management mode and organization lead to various problems in the traffic control of HZMB [4-6]. For the purpose of achieving unified management and control of traffic flow after the opening, it's necessary to build the structured, coordinated and ordered cross-border traffic control operation mode with well-defined duties and responsibilities.

\section{The scope and the segmented control philosophy}

The cross-border traffic control scope of the HZMB includes the offshore bridge and tunnel within mainland Chinese territory (from the Guangdong/Hong Kong border to the BCFs of Zhuhai and Macao), the Boundary Crossing Facilitates (BCF) at Hong Kong, Zhuhai and Macao; and the Link Roads in these three regions.

For the purpose of achieving the smooth transition of the traffic between the main part of the HZMB and the Link Road to Hong Kong, the project is divided into two sections to match the traffic control requirements between the main part of the HZMB and the Link Road to Hong Kong, as shown in Fig. 1. The $22.9 \mathrm{~km}$ bridge section (hereafter referred to as the bridge section) in the main part of the HZMB is the first section, and the west artificial island-tunnel-east artificial island-link road to Hong Kong is the second section (hereafter referred to as the cross-border section). Matching the structure characteristics and climate features of the HZMB, the segmented control philosophy could recognize all the related departments in the traffic control based on the location and scope of the incident as well as the collaborative traffic control requirements of the Link Road to Hong Kong, which is helpful to build the cross-border traffic control system. 


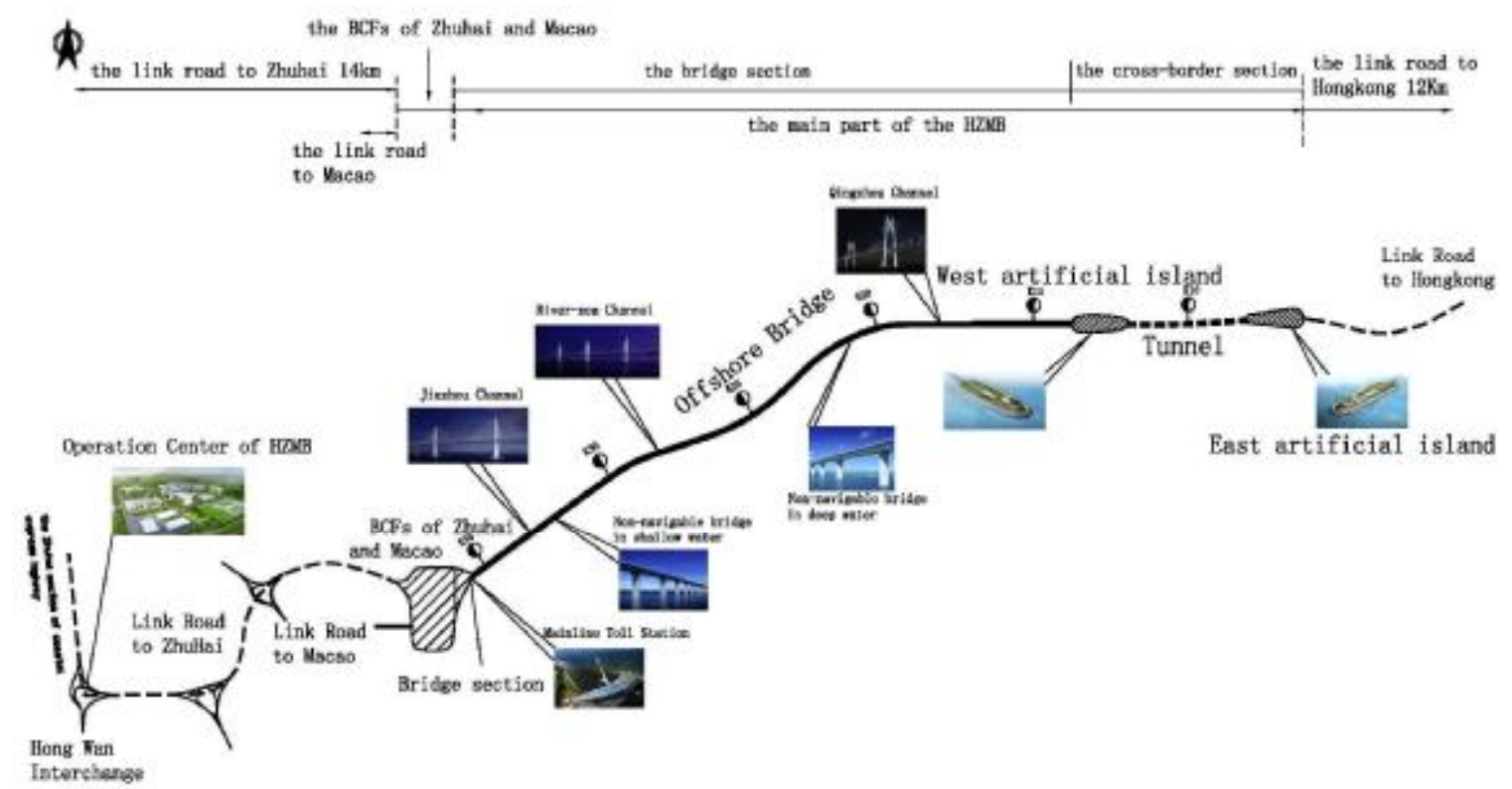

Fig. 1. Cross-border traffic segmented control scheme of the HZMB.

\section{Operation system in cross-border traffic control of the HZMB}

The cross-border traffic control of the HZMB is implemented by many organization and layered institution, which need to be integrated so as to form the layered operating system. By narrowing the range of the information publication and reducing the reuse of the information, the operating system could realize the effective communication and cross-border traffic control. Learn from the best practice of Hong Kong-Shenzhen Western Corridor (HK-SWC), the liaison officer is allocated to take charge the organization and coordination of related departments so as to smoothly ease the traffic while serious and major incidents [7-9].

The operation system in cross-border traffic control and emergency response of the HZMB is shown in Fig.2.

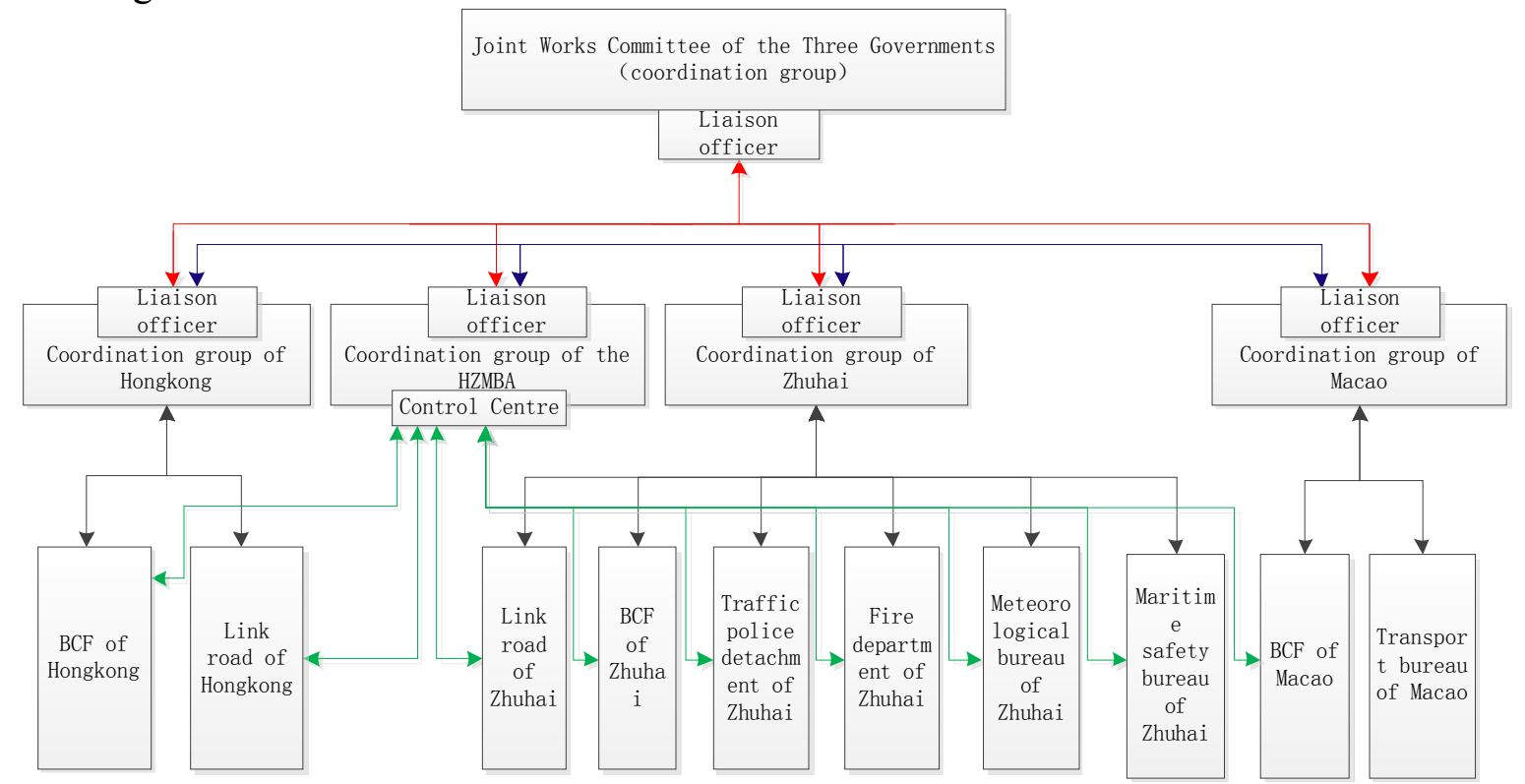

Fig. 2. Operation system in cross-border traffic control of the HZMB.

Every component of the operation system is connected by the black line. The routine or the usual traffic control could be implemented by the information interchange or the cooperation among the related departments, which is shown by the green line. The major traffic control incident should be reported to the corresponding liaison officer of the Governments of Guangdong, Hong Kong and 
Macao, and solved by the the communication among the liaison officers, which is shown by the blue line. The serious traffic control incident should be reported to the liaison officer of the Joint Works Committee of the Three Governments(JWCTG) and solved by the coordination among the liaison officers, which is shown by the red line.

\section{Operation Mode in cross-border traffic control of the HZMB}

According to the severity, the sphere of influence, the traffic control range, the related departments, the operation mode could be divided into three grades, as shown in Table 1.

Table 1 the cross-border traffic control operation mode of the HZMB

\begin{tabular}{|c|c|c|c|c|}
\hline Grade & Severity & Control measures & Related departments & Communication \\
\hline I & Serious & Close the HZMB & $\begin{array}{l}\text { Coordination group of } \\
\text { JWCTG, Related } \\
\text { departments and } \\
\text { coordination group of } \\
\text { Hongkong, Zhuhai, } \\
\text { Macao, and HZMBA, } \\
\text { HZMBA }\end{array}$ & $\begin{array}{l}\text { Liaison officer, } \\
\text { Information } \\
\text { interchange } \\
\text { platform }\end{array}$ \\
\hline II & Significant & Flow control & $\begin{array}{l}\text { Related departments } \\
\text { and coordination group } \\
\text { of Hongkong, Zhuhai, } \\
\text { Macao, and HZMBA, } \\
\text { HZMBA }\end{array}$ & $\begin{array}{l}\text { Liaison officer, } \\
\text { Information } \\
\text { interchange } \\
\text { platform }\end{array}$ \\
\hline III & Important & Speed limit & $\begin{array}{c}\text { HZMBA、 link road at } \\
\text { Hongkong }\end{array}$ & $\begin{array}{l}\text { Staff on duty, } \\
\text { Information } \\
\text { interchange } \\
\text { platform }\end{array}$ \\
\hline
\end{tabular}

\section{Summary}

The cross-border traffic control of the HZMB is implemented by HZMBA, the BCF and the link road at Hong Kong, Zhuhai and Macao, the government of Zhuhai, Guangdong, Hongkong, Macao, etc. While handling the incident and resuming the traffic as soon as possible are the most important thing based on the integration and the coordination mechanism of all those departments. In this paper, the operation system with the location of the liaison officer is present to exchange timely and accurate information cooperate with each other. According to the severity, the sphere of influence, the traffic control range, the related departments, the operation mode of the cross-border traffic control could be divided into three grades, which facilitates the actual operation. For the lack of similar cross-border project to be learned, both the operation system and the operation mode are incomplete, which need to be improved in the future operation of the HZMB.

\section{Acknowledgements}

This work was financially supported by No.3 Special Subject Study in the sub-topic 2 of the Key Technologies Research and Development Program of China (2011BAG07B05-2) and Preparation of the Operation and Maintenance Manual (Traffic Engineering). 


\section{References}

[1] Jia-qing Yu, Jie Huo, Qiang Shi .An Exploration on the Organizational Structure Design of the Hong Kong-Zhuhai-Macao Bridge Authority[C]// Proceedings of the 19th International Conference on Industrial Engineering and Engineering Management. IEEE Press, 2012: 872-876.

[2] Yu Lie. Crossing the Lingdingyang, HONG KONG-ZHUHAI-MACAO BRIDGE, 2011, (1), pp. $10-17$.

[3] Jiaqing $\mathrm{Yu}$, Jianzhong Cha \& Yiping Lu. Design synthesis approach based on process decomposition to design reuse. Journal of Engineering Design, 2012, 23(7): 526-543.

[4] N. Hussain, Carlos Wong, Matt Carter, Samuel Kwan, Tak-Wah Mak. Hong Kong Zhuhai Macao Link. Procedia Engineering, 2011, 14, pp. 1485-1492.

[5] Goold, M., Campbell, A. Do you have a well-designed organization. Harvard Business Review, 2002(R0203K): 5-11.

[6] NEC Provides Traffic Control System for the Shin-Tomei Expressway.Available at: http://www.nec.com/en/press/201209/global_20120920_01.html.

[7] Lee, Joseph; Kong, Alex; Chan, Eric. Hong Kong-Shenzhen Western Corridor and Deep Bay Link: Design Development and Environmental Challenges. Proceedings of IABSE Symposium Shanghai 2004, Metropolitan Habitats and Infrastructure, pp. 25-30(6).

[8] J. Schesser, D.N. Tanner. Hampton roads traffic surveillance and control system. IEEE Transactions on Vehicular Technology, 2014.

[9] Schwaninger Markus. Design for viable organizations: The diagnostic power of the viable system model. The International Journal of Systems \& Cybernetics, 2006, 35(7-8): 955-966. 